\title{
Compulsory treatment of drug addictions in Southeast Asian Countries
}

\author{
Karsten Lunze $^{\mathrm{a}}$, Olivier Lermet ${ }^{\mathrm{b}}$, Vladanka Andreeva ${ }^{\mathrm{c}}$, Fabienne Hariga $^{\mathrm{d}}$
}

\author{
${ }^{a}$ Karsten Lunze, MD, MPH, DrPH, FACPM, FAAP \\ Boston University School of Medicine \\ 801 Massachusetts Ave., Crosstown 2079 \\ Boston, MA 02118, USA \\ karsten.lunze@post.harvard.edu
}

${ }^{\mathrm{b}}$ Olivier Lermet

Regional Adviser, HIV/AIDS, United Nations Office on Drugs and Crime

Regional Office for Southeast Asia and the Pacific, UN Secretariat Building, 3rd Floor

Rajdamnern Nok Avenue

Bangkok 10200, Thailand

olivier.lermet@unodc.org

${ }^{\mathrm{c}}$ Vladanka Andreeva DMD, MPH

UNAIDS, Regional Support Team, Asia and the Pacific, UN Building Room 906

Rajadamnern Nok Avenue

10200 Bangkok Thailand

andreevav@unaids.org

${ }^{\mathrm{d}}$ Fabienne Hariga, MD, MPH

Senior Expert, HIV/AIDS Section, United Nations Office on Drugs and Crime

Room D1426, P.O Box 500 A-1400 Vienna, AUSTRIA

fabienne.hariga@unodc.org 


\title{
Compulsory treatment of drug addictions in Southeast Asian Countries
}

\author{
Abstract \\ Background:
}

Several Southeast Asian countries have implemented compulsory drug detention centres in which people who use or are suspected of using drugs, mainly amphetamine-type stimulants, are confined without their consent and in most cases without due process and clinical evaluation of their substance use disorder.

Given these facilities' lack of access to evidence-based addiction treatment, and the human rights implications of peoples' detention without consent under the pretext of treatment, international organizations have called for their closure. The aim of this study was to estimate recent numbers of compulsory drug treatment centres and of people in compulsory treatment in the region.

Methods:

We conducted an analysis of cross-sectional, governmental data collected from seven countries in the region with compulsory drug detention centres, namely Cambodia, China, Lao PDR, Malaysia, the Philippines, Thailand and Viet Nam. We computed descriptive data provided by government representatives for the period between 2012 and 2014.

Results:

The total number of people in compulsory detention centres decreased by only $4 \%$ between 2012 and 2014, and in 2014 over 450,000 people were detained in 948 facilities in the seven countries. While few countries decreased the number of compulsory detention centres, most countries increased the number of people detained.

Conclusions:

In spite of international calls for the closure of compulsory detention centres, the number of facilities and detained people remained high in the seven countries included in the analysis. These officially reported figures are concerning regarding access to effective addiction treatment and given the potential for human rights abuses within compulsory detention centers.

Further concerted policy and advocacy efforts should support transition of treatment for people with addictions towards evidence-based addiction therapies. Expansion of existing addiction and HIV services in the community rather than compulsory treatment modalities will effectively address the region's drug and HIV burden.

Key words: mandatory drug treatment, people who inject drugs, PWUD, PWID 


\section{Background}

The use of opiates and particularly of amphetamine-type stimulants (ATS) like methaphetamine continues to be a major problem in Southeast Asian and Pacific countries, which represents the largest market worldwide for ATS. China, Malaysia, Myanmar and Viet Nam report heroin as leading substance among people who use drugs (PWUD), and the use of opiates has been increasing in the region. Among PWUD, rates of injecting drug use have been growing in the region, where an estimated 3.15 million people inject drugs, accounting for a quarter of people injecting worldwide (UNODC 2016).

In HIV epidemics concentrated among PWUD, harm reduction through sufficient provision of clean syringes and effective addiction treatment have proven to limit HIV transmission among HIV-positive PWUD (Wodak and McLeod 2008). Effective opioid addiction treatment is based on agonist treatment with methadone or buprenorphine that reduces craving for, and use of, heroin or other illicit opiates, as well as drug related mortality and morbidities (Gowing, Farrell et al. 2011). Methadone also reduces the risk of HIV infection among seronegative PWUD by more than 50\% (MacArthur, Minozzi et al. 2012). Stimulant use disorders require skilled diagnosis and treatment based on behavioral and pharmacological therapies.

As part of their response to drug use and the associated burden, many countries in the Southeast Asian and Pacific region have implemented compulsory drug detention facilities in which people suspected to use drugs or people who use drugs (PWUD) are held without their consent. These are closed, government or privately run facilities in which PWUD are detained without alternatives or consent for the declared purpose of "drug treatment" or "rehabilitation" and without the possibility to leave the centre if they wish. Such facilities are also referred to as compulsory drug detention centres, compulsory drug treatment or rehabilitation or correction centres, re-education through labour camps (in some cases renamed drug rehabilitation centers), boot camps, long-term detention centres, or other terms. Almost all compulsory drug detention facilities do not provide harm reduction or evidence-based addiction treatment (Hall, Babor et al. 2012).

Compulsory treatment is a form of mandatory treatment that lacks consent for treatment and are defined by UNODC as treatment "that does not allow the individual to decline treatment or choose the type that they receive" (UNODC 2009). A position paper issued by the Australian National Council on Drugs defined compulsory treatment as "court-ordered treatment as part of sentencing orders, and civil commitment, in which cases treatment interventions occur without the consent of those receiving them”(Australian National Council on Drugs 2014). The United Nations Asia and Far East Institute for 
the Prevention of Crime and the Treatment of Offenders (UNAFEI) and the Japanese Ministry of Justice conducted a survey of drug treatment in China (Hong Kong), Korea, Malaysia, Singapore and Thailand, in which compulsory treatment is defined as institutional or community-based treatment "which provides drug abuser treatment without the consent of its clients [...], in relation to the criminal justice system" (UNAFEI 2005).

In some countries, the referral process for sending people to compulsory drug detention facilities occurs outside the court system, a deprivation of liberty that violates the minimum standards of due process within the International Covenant on Civil and Political Rights (Nosyk B, Min JE, et al. 2015). Compulsory treatment modalities do not allow for comprehensive assessment and diagnosis to develop and implement individual treatment plans, which need to take into account the stage and severity of the disease, somatic and mental health status, individual character and personality traits, vocational and employment status, family and social integration, and legal situation (UNODC and WHO 2008). Likewise, treatment without consent does not consider patient's readiness for change and does not allow motivational strategies; and thus misses the opportunity to facilitate, as recommended by professional associations dedicated to addiction treatment, linkage of people with addictions to an appropriate level of care, e.g., outpatient vs. more intense inpatient or residential care (Mee-Lee 2013).

Compulsory drug detention centres for PWUD rarely provide any evidence-based forms of treatment and differ from other types of mandatory treatment, such as quasi-compulsory treatment offered as an alternative to prison. The Council of Europe defined 'quasi-compulsory' treatment (QCT) of drugdependent offenders as "any form of drug treatment that is ordered, motivated or supervised by the criminal justice system" (McSweeney 2008). Research on quasi-compulsory treatment is relatively rare, methodologically limited due to its inherent selection bias (as people opt into this treatment), and its effectiveness in comparison to voluntary treatment is unclear (Stevens, Berto et al. 2005). Mandatory treatment modalities further include civil commitment to drug treatment (legally sanctioned, involuntary commitment of a non-offender into treatment for drug or alcohol dependence), court-mandated treatment (of an offender, required by a court order), and coerced treatment (in the presence of an offence, and limited degree of choice in the individual's decision to access treatment or face legal sanctions) (Pritchard, Mugavin et al. 2007). In contrast to compulsory treatment, mandatory (legally coerced) treatment as an alternative to criminal justice sanctions represents an opportunity offered by the community to drug users and drug dependent individuals to accept some form of assistance (Hall and Lucke 2010). It usually allows some choice of treatment, rehabilitation, education, and health care, and does not force patients to treatment without their consent (UNODC 2009). 
A recent review evaluated the clinical effectiveness compulsory treatment, referring to the detention in closed facilities in which people who use drugs are enclosed without an alternative to incarceration and are administered involuntary drug addiction treatment in any form without their consent. In contrast to some of the above-described forms of mandatory treatment, current evidence does not support that compulsory treatment modalities are effective for addiction treatment, and some studies even suggest it to be harmful (Werb, Kamarulzaman et al. 2016).

Consequently, given these facilities' lack of clinical effectiveness in treating addiction disorders and the problematic human rights implications of peoples' detention for addiction treatment without consent (Lunze, Idrisov et al. 2016), twelve United Nations organizations issued a joint statement in 2012 on compulsory drug detention and rehabilitation centres, calling for their closure and replacement with voluntary, evidence-informed and rights-based health and social services in the community (UNODC 2012). Our goal was to follow-up on this call and to assess the magnitude of PWUD currently in compulsory treatment. The aim of this study was therefore to estimate recent numbers of compulsory drug treatment centres and of people in compulsory treatment in the Southeast Asian and Pacific region.

\section{Methods}

We conducted a cross-sectional study in the context of a regional consultation on compulsory drug detention centres in September 2015 in Manila, Philippines, convened by UNODC, UNAIDS and the UN Economic and Social Commission for Asia and the Pacific. Countries in the region where compulsory drug detention centres exist participated in the survey, namely Cambodia, China, Lao PDR, Malaysia, the Philippines, Thailand and Viet Nam. Using a standardized data collection form and the above cited definition of compulsory treatment ("detention in closed facilities in which people who use drugs are enclosed without an alternative to incarceration and are administered involuntary drug addiction treatment in any form without their consent"), we collected data on the number of facilities, number of people held in these facilities, and length of stay of individuals in these centers.

We used the country-level data set collected to conduct a cross-sectional analysis at the three time points for which complete data was available, i.e., for 2012, 2013, and 2014. We computed descriptive data provided by government representatives for the time period between 2012 and 2014.

\section{Results}


Seven countries reported data, namely Cambodia, China, Lao PDR, Malaysia, the Philippines, Thailand and Viet Nam. Figures are reported for the entire period from 1 January through 31 December of each year.

The number of detention centers in the seven countries remained stable at over 900 facilities (Table 1). While two countries slightly increased the number of facilities, others like Viet Nam decreased them during the study period between 2012 and 2014.

Table 1: Number of Compulsory Drug Treatment Detention Centres

\begin{tabular}{|l|c|c|c|}
\hline & $\mathbf{2 0 1 2}$ & $\mathbf{2 0 1 3}$ & $\mathbf{2 0 1 4}$ \\
\hline Cambodia & 10 & 10 & 10 \\
\hline China & 700 & 700 & 700 \\
\hline Laos & 9 & 10 & 11 \\
\hline Malaysia & 21 & 18 & 21 \\
\hline Philippines & 37 & 37 & 37 \\
\hline Thailand & 87 & 86 & 86 \\
\hline Viet Nam & 110 & 105 & 83 \\
\hline Total & $\mathbf{9 7 4}$ & $\mathbf{9 6 6}$ & $\mathbf{9 4 8}$ \\
\hline
\end{tabular}

The total number of people in compulsory treatment centres decreased by only $4 \%$ between 2012 and 2014, and remained at over 450,000 detained people (Table 2). The countries who decreased the number of facilities also decreased the number of people in compulsory detention. However, most countries in this sample increased the number of people detained.

Table 2: Number of People held in Compulsory Drug Treatment Detention Centres

\begin{tabular}{|l|l|l|l|}
\hline & $\mathbf{2 0 1 2}$ & $\mathbf{2 0 1 3}$ & $\mathbf{2 0 1 4}$ \\
\hline Cambodia & 2,600 & 2,713 & 3,249 \\
\hline China & 319,000 & 319,000 & 319,000 \\
\hline Laos & 3,915 & 4,718 & 5,339 \\
\hline Malaysia & 5,473 & 5,136 & 5,753 \\
\hline Philippines & 2,744 & 3,266 & 4,392 \\
\hline Thailand & 112,589 & 131,496 & 96,680 \\
\hline Viet Nam & 27,920 & 29,273 & 21,401 \\
\hline Total & $\mathbf{4 7 4 , 2 4 1}$ & $\mathbf{4 9 5 , 6 0 2}$ & $\mathbf{4 5 5 , 8 1 4}$ \\
\hline
\end{tabular}


In the countries who provided data, the typical length of stay varied widely (Table 3). Detention times ranged from 3 to 24 months. Since detention duration were reported as typical time periods, we could not calculate a summary statistics.

\begin{tabular}{|l|c|}
\hline & Months \\
\hline Cambodia & 6 \\
\hline China & $12-24$ \\
\hline Laos & $3-6$ \\
\hline Malaysia & $9-12$ \\
\hline Philippines & 8 \\
\hline Thailand & 6 \\
\hline Viet Nam & $12-24$ \\
\hline
\end{tabular}

\section{Discussion}

This observational study documents the latest available, government-reported number of people detained in compulsory centers across the region in 2014 at over 450,000. The total number of people in compulsory treatment centres registered a minor decrease between 2012 and 2014, and the number of compulsory facilities remained high at over 900. In comparison, a previous study quantifying compulsory drug detention in the region reported 235,000 people detained in over 1,000 compulsory drug detention centers in East and Southeast Asia (Amon, Pearshouse et al. 2014). That study also reported that PWUD were held up to five years without clinical determination of drug dependency or due process, and without access to evidence-based drug treatment or other basic health services. In this study, reported detention duration ranged from one to 24 months. Overall, this study indicates slow progress towards rights-based and evidence-informed responses to drug use and addiction.

Despite the efforts of several countries to explore alternatives to compulsory detention centres, none appears to be phasing out compulsory facilities. Countries struggling to build momentum towards that goal have highlighted numerous challenges, including growing use of amphetamine-type stimulants, a lack of human resources trained in evidence-based approaches, and the poor quality of programme monitoring and evaluation systems to assess the progress of transition (Report of the Third Regional Consultation on Compulsory Centres for Drug Users in Asia and the Pacific). 
Compulsory drug treatment is by no means limited to the Asian and Pacific regions. Internationally, more than $2 / 3$ of all countries have (mostly criminal) legislation for compulsory drug treatment (Israelsson and Gerdner 2012). Considering compulsory treatment as involuntary without alternative, it is being reported in the published literature from many countries globally, including several within the EU, in the USA and Canada, Australia, New Zealand, and Asian countries (Leukefeld and Tims 1988; Fischer, Roberts et al. 2002; Birgden and Grant 2010).

A 2008 survey conducted by the Criminal Justice Platform (PGCJP) of the Council of Europe's (CoE) Pompidou Group (the CoE Co-operation Group to Combat Drug Abuse and Illicit Trafficking in Drugs) on legislation and guidelines related to drug treatments mandated by the criminal justice systems found that most European countries and $\mathrm{CoE}$ member states have national legislation and guidelines governing the 'quasi-compulsory' treatment of drug-dependent offenders (McSweeney 2008). However, even in Europe, only five of 16 countries analyzed addressed best-practice principles as set forth by UNODC (UNODC 2007).

In an advocacy brief, the International Drug Policy Consortium summarized that evidence-based treatment programmes remain scarce in Latin American countries. In several countries, people who use drugs are often forced to detoxification in therapeutic communities that use religious beliefs as base for drug treatment. In countries such as Guatemala, Peru and Ecuador, PWUD often are involuntarily placed in compulsory rehabilitation centres based on religious beliefs. In Mexico, carrying minor amounts of drugs for personal use is not illegal, but person with higher than permitted amounts can be sent to compulsory drug treatment programmes (IDPC 2014).

In compulsory drug treatment centres in Southeast Asian and Pacific countries, standards of treatment vary but usually do not include evidence-based addiction or HIV treatment. A review of compulsory treatment in centres in Cambodia, China, Malaysia and Viet Nam concluded that these closed setting centres lack effective drug treatment or HIV services (WHO 2009). A study from Malaysia found that only a minority of detainees were evaluated for HIV or tuberculosis and none received treatment for either, while $95 \%$ of participants met criteria for opioid dependence and none received agonist addiction therapy (Fu, Bazazi et al. 2012). Reports also found forced labor (in Vietnam, and some in Cambodia and China), physical and in some instances sexual abuse in these camps (Pearshouse 2009; Amon, Pearshouse et al. 2014). Given these reports, the validity of research from China claiming higher quality of life of detainees in compulsory treatment centers than in community-based treatment facilities (Xiao, Wu et al. 2009) has been disputed (Pearshouse and Amon 2012). 
Consistent with the lack of evidence based treatment in compulsory treatment facilities, there is limited evidence on reduction of substance use and HIV risks associated with compulsory treatment. In addition to raising concerns about ethics and human rights violations (Hall, Babor et al. 2012; Jurgens and Csete 2012), detention for the purpose of drug treatment seems to do little to reduce substance use and HIV risks. Consistent with an earlier study conducted in Vietnam (Tran, Williams et al. 1998), in a study conducted in Thailand, those with a past experience of compulsory drug detention had high rates of relapse into drug use (96\%) (Csete, Kaplan et al. 2011). Another study in Thailand confirmed that compulsory detention leads only to short term drug cessation and is associated with high drug use relapse rates (Fairbairn, Hayashi et al. 2014). Upon exit from camps, a history of compulsory drug detention was associated with avoiding healthcare among Thai PWID (Kerr, Hayashi et al. 2013). Although almost all detainees in Guangxi Autonomous Region, China, get mandatory testing, many are unaware that this includes HIV testing and are unaware of their test results (Yap, Reekie et al. 2015). Another study from South China found the number of compulsory drug abstinence treatments to be positively associated with HIV status (Chen, Tuner et al. 2013).

Few countries offer agonist opioid treatment in detention centers, with the exception of Iran, where compulsory mandatory treatment centers offer methadone therapy (Eskandarieh, Jafari et al. 2015). Other countries have implemented policies to transition compulsory drug treatment centres to community-based voluntary treatment. Recent reports found recent trends in East Asia evolving towards community-based voluntary treatment in countries such as Malaysia (Ghani, Brown et al. 2015; Kamarulzaman and McBrayer 2015). Nine countries of the region, including Cambodia, China, Indonesia, Lao PDR, Malaysia, Myanmar, the Philippines, Thailand and Viet Nam, have committed to transition from compulsory detention treatment models towards voluntary community-based treatment services on the basis of expanded community-based voluntary addiction care in health centres.

Rigorous evidence indicates that voluntary, community-based treatment programmes are more effective in treating addictions than compulsory treatment modalities. A prospective observational study in Malaysia comparing outcomes of PWUD in compulsory drug detention centers with those in voluntary drug treatment centres found that those in compulsory detention had significantly more rapid relapse to opioid use post-release compared with those in voluntary, community-based treatment (Wegman, Altice et al. 2016). This adds to the growing amount of evidence indicating ineffectiveness and harms created by compulsory treatment and associated adverse health, social, economic and criminal outcomes (Klag, O'Callaghan et al. 2005; WHO 2009; UNOCD RC EAP 2010; Bergenstrom and Vumbaca 2016).

Our study has several limitations. The study was limited to a subset of countries in the region, therefore the number of centres and people in detention can be assumed to be underestimated. Likewise, the 
country-level data for this study were provided by governments and not verified independently. The aggregate report of data for facilities and people in detention did not allow for more nuanced analysis assessing, e.g., demographics, determinants of detention and associated risks.

\section{Conclusion}

In spite of international calls for the closure of compulsory treatment centres because of their lack of effectiveness and human rights concerns, the number of detention centers and detained PWUD reported by governments in the region remains high in the seven countries studied. The number of detention centers and detainees in these countries has hardly decreased, underscoring the urgent need for accelerating transition to voluntary community-based treatment services.

The slow progress towards rights-based and evidence-informed responses to drug use and addictions requires urgent attention and concerted policy efforts. Advocacy and community strengthening should engage a range of partners at the country level, leveraging the participation of civil society organizations and communities of people who use drugs to support the goal of effective, community-based treatment modalities.

\section{Author Declaration}

We declare that all authors have contributed to, seen and approved the final version of the manuscript.

\section{Conflict of Interest}

We declare no potential conflicts of interest. This work was funded by UNODC. OL and FH are employees of UNODC, whose declared goal is the transition from compulsory drug detention centres to evidence based and voluntary forms of treatment for people who use drugs. OL and FH contributed to the study design; the collection, analysis and interpretation of data; the writing of the report; and shared in the decision to submit the article for publication. 


\section{References}

Amon, J., R. Pearshouse, et al. (2014). "Compulsory drug detention centers in China, Cambodia, Vietnam, and Laos: health and human rights abuses." Health Hum Rights 15(2): 124-37.

Australian National Council on Drugs (2014). "Mandatory Drug Treatment, Position Statement " accessed online at http://www.ancd.org.au/images/PDF/Positionpapers/Mandatory_Treatment.pdf.

Bergenstrom, A. and G. Vumbaca (2016). "Compulsory drug detention centres: time to question their continued use?" Lancet Glob Health 5(2): e123-e124.

Birgden, A. and L. Grant (2010). "Establishing a compulsory drug treatment prison: Therapeutic policy, principles, and practices in addressing offender rights and rehabilitation." Int J Law Psychiatry 33(5-6): 341-9.

Chen, H. T., N. Tuner, et al. (2013). "Correlations between compulsory drug abstinence treatments and HIV risk behaviors among injection drug users in a border city of South China." AIDS Educ Prev 25(4): 336-48.

Csete, J., K. Kaplan, et al. (2011). "Compulsory drug detention center experiences among a communitybased sample of injection drug users in Bangkok, Thailand." BMC Int Health Hum Rights 11: 12.

Eskandarieh, S., F. Jafari, et al. (2015). "Compulsory maintenance treatment program amongst Iranian injection drug users and its side effects." Int J High Risk Behav Addict 3(4): e21765.

Fairbairn, N., K. Hayashi, et al. (2014). "Compulsory drug detention and injection drug use cessation and relapse in Bangkok, Thailand." Drug Alcohol Rev 34(1): 74-81.

Fischer, B., J. V. Roberts, et al. (2002). "Compulsory drug treatment in Canada: historical origins and recent developments." Eur Addict Res 8(2): 61-8.

Fu, J. J., A. R. Bazazi, et al. (2012). "Absence of antiretroviral therapy and other risk factors for morbidity and mortality in Malaysian compulsory drug detention and rehabilitation centers." PLoS One 7(9): e44249.

Ghani, M. A., S. E. Brown, et al. (2015). "An exploratory qualitative assessment of self-reported treatment outcomes and satisfaction among patients accessing an innovative voluntary drug treatment centre in Malaysia." Int J Drug Policy 26(2): 175-82.

Gowing, L., M. F. Farrell, et al. (2011). "Oral substitution treatment of injecting opioid users for prevention of HIV infection." Cochrane Database Syst Rev(8): CD004145.

Hall, W., T. Babor, et al. (2012). "Compulsory detention, forced detoxification and enforced labour are not ethically acceptable or effective ways to treat addiction." Addiction 107(11): 1891-3.

Hall, W. and J. Lucke (2010). "Legally Coerced Treatment for Drug Using Offenders: Ethical and Policy Issues." Crime and Justice Bulletin(144): 12.

IDPC (2014). "Compulsory rehabilitation in Latin America: An unethical, inhumane and ineffective practice." accessed at http://idhdp.com/media/1236/idpc-advocacy-note compulsoryrehabilitation-latin-america english.pdf.

Israelsson, M. and A. Gerdner (2012). "Compulsory commitment to care of substance misusers: international trends during 25 Years." Eur Addict Res 18(6): 302-21.

Jurgens, R. and J. Csete (2012). "In the name of treatment: ending abuses in compulsory drug detention centers." Addiction 107(4): 689-91.

Kamarulzaman, A. and J. L. McBrayer (2015). "Compulsory drug detention centers in East and Southeast Asia." Int J Drug Policy 26 Suppl 1: S33-7.

Kerr, T., K. Hayashi, et al. (2013). "The impact of compulsory drug detention exposure on the avoidance of healthcare among injection drug users in Thailand." Int J Drug Policy 25(1): 171-4. 
Klag, S., F. O'Callaghan, et al. (2005). "The use of legal coercion in the treatment of substance abusers: an overview and critical analysis of thirty years of research." Subst Use Misuse 40(12): 1777-95.

Leukefeld, C. G. and F. M. Tims (1988). "An introduction to compulsory treatment for drug abuse: clinical practice and research." NIDA Res Monogr 86: 1-7.

Lunze, K., B. Idrisov, et al. (2016). "Mandatory addiction treatment for people who use drugs: global health and human rights analysis." BMJ 353: i2943.

MacArthur, G. J., S. Minozzi, et al. (2012). "Opiate substitution treatment and HIV transmission in people who inject drugs: systematic review and meta-analysis." BMJ 345: e5945.

McSweeney, T. (2008). "Guidelines on the 'quasicompulsory' treatment of adult drug-dependent offenders. Results from a survey of Council of Europe Member States."

Mee-Lee, D. (2013). "The ASAM Criteria: Treatment Criteria for Addictive, Substance-Related, and CoOccurring Conditions. ISBN: 978-1-61702-197-8".

Pearshouse, R. (2009). "'Patients, not criminals"? An assessment of Thailand's compulsory drug dependence treatment system." HIV AIDS Policy Law Rev 14(1): 11-7.

Pearshouse, R. and J. J. Amon (2012). "The ethics of research in compulsory drug detention centres in Asia." J Int AIDS Soc 15(2): 18491.

Pritchard, E., J. Mugavin, et al. (2007). "Compulsory treatment in Australia: a discussion paper on the compulsory treatment of individuals dependent on alcohol and/or other drugs " ANCD research paper 14(accessed online at http://www.ancd.org.au/images/PDF/Researchpapers/rp14 compulsory treatment.pdf?phpMy Admin=rGQ2XkOOsKjMp24r2sFwuVc5ibb).

Stevens, A., D. Berto, et al. (2005). "Quasi-compulsory treatment of drug dependent offenders: an international literature review." Subst Use Misuse 40(3): 269-83.

Tran, S. D., A. B. Williams, et al. (1998). "Risk factors for HIV seropositivity in a sample of drug users in drug treatment in Ho Chi Minh City, Vietnam." J Acquir Immune Defic Syndr Hum Retrovirol 17(3): 283-7.

UNAFEI (2005). "Research on the Trends in Drug Abuse and Effective Measures for the Treatment of the Drug Abusers in Asian Countries - An Analysis of Innovative Measures for the Treatment of Drug Abusers." United Nations Asia and Far East Institute for the Prevention of Crime and the Treatment of Offenders; and the Research Division of the Research and Training Institute.

UNOCD RC EAP (2010). "Evidence from Compulsory Centres for Drug Users in East and South East Asia. Background Paper prepared by UNODC RE EAP for the Regional Consultation on Compulsory Centres for Drug Users, 14-16 December, 2010, Bangkok, Thailand. Accessed at http://www.unaids.org.cn/pics/20130719153407.pdf ".

UNODC (2007). "Handbook of basic principles and promising practices on Alternatives to Imprisonment." accessed at http://www.unodc.org/pdf/criminal justice/Handbook of Basic Principles and Promising Pra ctices on Alternatives to Imprisonment.pdf and http://www.unrol.org/files/Alternatives emprisonment.\%20french\%20version.pdf.

UNODC (2009). "From coercion to cohesion: Treating drug dependence through health care, not punishment " accessed at http://www.unodc.org/docs/treatment/Coercion Ebook.pdf.

UNODC (2012). "Joint Statement on compulsory drug detention and rehabilitation centres." accessed at https://www.unodc.org/documents/southeastasiaandpacific//2012/03/drug-detentioncentre/JC2310 Joint Statement6March12FINAL En.pdf.

UNODC (2016). "World Drug Report 2016." accessed online at https://www.unodc.org/wdr2016.

UNODC and WHO (2008). "Principles of Drug Dependence Treatment. Accessed at http://www.unodc.org/documents/drug-treatment/UNODC-WHO-Principles-of-DrugDependence-Treatment-March08.pdf." 
Wegman, M. P., F. L. Altice, et al. (2016). "Relapse to opioid use in opioid-dependent individuals released from compulsory drug detention centres compared with those from voluntary methadone treatment centres in Malaysia: a two-arm, prospective observational study." Lancet Glob Health 5(2): e198-e207.

Werb, D., A. Kamarulzaman, et al. (2016). "The effectiveness of compulsory drug treatment: A systematic review." Int J Drug Policy 28: 1-9.

WHO (2009). "Assessment of compulsory treatment of people who use drugs in Cambodia, China, Malaysia and Viet Nam: an application of selected human rights principles."

Wodak, A. and L. McLeod (2008). "The role of harm reduction in controlling HIV among injecting drug users." AIDS 22 Suppl 2: S81-92.

Xiao, L., Z. Wu, et al. (2009). "[Comparison of quality of life for drug addicts in methadone maintenance treatment clinics, community and compulsory detoxification institutions in Sichuan Province]." Wei Sheng Yan Jiu 38(1): 67-70.

Yap, L., J. Reekie, et al. (2015). "HIV testing in re-education through labour camps in Guangxi Autonomous Region, China (a cross-sectional survey)." Sex Transm Infect. 